University of Nebraska - Lincoln

DigitalCommons@University of Nebraska - Lincoln

USDA National Wildlife Research Center - Staff Publications
U.S. Department of Agriculture: Animal and Plant Health Inspection Service

October 2001

\title{
Effects of Trapping and Subsequent Short-Term Confinement Stress on Plasma Corticosterone in the Brown Treesnake (Boiga irregularis) on Guam
}

\section{Tom Mathies}

U.S. Department of Agriculture, Animal Plant Health Inspection Service, Wildlife Services, National Wildlife Research Center

Todd A. Felix

U.S. Department of Agriculture, Animal Plant Health Inspection Service, Wildlife Services, National Wildlife Research Center

Valentine A. Lance

Center for Reproduction of Endangered Species, Zoological Society of San Diego

Follow this and additional works at: https://digitalcommons.unl.edu/icwdm_usdanwrc

Part of the Environmental Sciences Commons

Mathies, Tom; Felix, Todd A.; and Lance, Valentine A., "Effects of Trapping and Subsequent Short-Term Confinement Stress on Plasma Corticosterone in the Brown Treesnake (Boiga irregularis) on Guam" (2001). USDA National Wildlife Research Center - Staff Publications. 561.

https://digitalcommons.unl.edu/icwdm_usdanwrc/561

This Article is brought to you for free and open access by the U.S. Department of Agriculture: Animal and Plant Health Inspection Service at DigitalCommons@University of Nebraska - Lincoln. It has been accepted for inclusion in USDA National Wildlife Research Center - Staff Publications by an authorized administrator of DigitalCommons@University of Nebraska - Lincoln. 


\title{
Effects of Trapping and Subsequent Short-Term Confinement Stress on Plasma Corticosterone in the Brown Treesnake (Boiga irregularis) on Guam
}

\author{
Tom Mathies ${ }^{b, a, 1}$, Todd A. Felix ${ }^{a}$ and Valentine A. Lance ${ }^{c}$ \\ ${ }^{a}$ U.S. Department of Agriculture, Animal Plant Health Inspection Service, Wildlife Services, \\ National Wildlife Research Center, 4101 LaPorte Avenue, Fort Collins, Colorado, 80532- \\ 2154 \\ ${ }^{\mathrm{b}}$ Department of Clinical Sciences, Colorado State University, Fort Collins, Colorado, 80532- \\ 1620 \\ ${ }^{\mathrm{c}}$ Center for Reproduction of Endangered Species, Zoological Society of San Diego, P.O. Box \\ 120551, San Diego, California, 92112
}

Accepted 23 July 2001. ; Available online 4 March 2002.

\begin{abstract}
The effects of capture in a live trap and subsequent handling stress on plasma concentrations of corticosterone and other sex steroids were examined in wild male and female brown treesnakes (Boiga irregularis), an introduced species on Guam that has been implicated in the extirpation or decline of many of that island's vertebrate species. Males and females that spent 1 night in a trap had plasma levels of corticosterone about four and two times higher, respectively, than those of the respective free-ranging controls. Mean plasma levels of corticosterone of snakes that had spent 3 nights in a trap were intermediate between, but not significantly different from, those of snakes that had spent 1 night in a trap and free-ranging snakes, suggesting that some acclimation to capture occurred during this period. Snakes that were taken from traps and held in collecting bags for $10 \mathrm{~min}$ and $2 \mathrm{~h}$ prior to blood sampling had levels of corticosterone about two and three times higher, respectively, than those of control snakes that were taken from traps and bled immediately. Concentrations of plasma corticosterone in free-ranging females were about two times higher than those of males but were well within the range of basal levels observed in other reptiles. Few snakes of potential reproductive size were reproductive (males: 1 of 35; females: 2 of 33), and plasma concentrations of testosterone and progesterone in nonreproductive males and females, respectively, were accordingly low. The possible relationship between corticosterone and these sex steroids, therefore, could not be adequately assessed, although there was a positive relationship between plasma progesterone and corticosterone in the nonreproductive females. Nonetheless, as a prerequisite for studies on the seasonal hormonal cycles of this species on Guam, our observations raise the possibility that the stress caused by trapping could affect the levels of other sex steroids and that, therefore, such studies should use free-ranging individuals.
\end{abstract}

Author Keywords: invasive species; reproduction; reptile; snake; stress response 


\title{
Effects of Trapping and Subsequent Short-Term Confinement Stress on Plasma Corticosterone in the Brown Treesnake (Boiga irregularis) on Guam
}

\author{
Tom Mathies, ${ }^{*}+, 1$ Todd A. Felix, ${ }^{*}$ and Valentine A. Lance $\ddagger$ \\ *U.S. Department of Agriculture, Animal Plant Health Inspection Service, Wildlife Services, National Wildlife Research \\ Center, 4101 LaPorte Avenue, Fort Collins, Colorado 80532-2154; †Department of Clinical Sciences, Colorado State \\ University, Fort Collins, Colorado 80532-1620; and $¥$ Center for Reproduction of Endangered Species, Zoological Society \\ of San Diego, P.O. Box 120551, San Diego, California 92112
}

Accepted July 23, 2001

The effects of capture in a live trap and subsequent handling stress on plasma concentrations of corticosterone and other sex steroids were examined in wild male and female brown treesnakes (Boiga irregularis), an introduced species on Guam that has been implicated in the extirpation or decline of many of that island's vertebrate species. Males and females that spent 1 night in a trap had plasma levels of corticosterone about four and two times higher, respectively, than those of the respective free-ranging controls. Mean plasma levels of corticosterone of snakes that had spent 3 nights in a trap were intermediate between, but not significantly different from, those of snakes that had spent 1 night in a trap and free-ranging snakes, suggesting that some acclimation to capture occurred during this period. Snakes that were taken from traps and held in collecting bags for $10 \mathrm{~min}$ and $2 \mathrm{~h}$ prior to blood sampling had levels of corticosterone about two and three times higher, respectively, than those of control snakes that were taken from traps and bled immediately. Concentrations of plasma corticosterone in free-ranging females were about two times higher than those of males but were well within the range of basal levels observed in other reptiles. Few snakes of potential reproductive size were reproductive (males: 1 of 35; females: 2 of 33), and plasma concentrations of

\footnotetext{
${ }^{1}$ To whom correspondence should be addressed. Fax: 970-2666157. E-mail: tom.c.mathies@aphis.usda.gov.
}

testosterone and progesterone in nonreproductive males and females, respectively, were accordingly low. The possible relationship between corticosterone and these sex steroids, therefore, could not be adequately assessed, although there was a positive relationship between plasma progesterone and corticosterone in the nonreproductive females. Nonetheless, as a prerequisite for studies on the seasonal hormonal cycles of this species on Guam, our observations raise the possibility that the stress caused by trapping could affect the levels of other sex steroids and that, therefore, such studies should use free-ranging individuals. 02001 Academic Press

Key Words: invasive species; reproduction; reptile; snake; stress response.

\section{INTRODUCTION}

The brown treesnake (Boiga irregularis) is a primarily nocturnal and arboreal colubrid native to parts of Melanesia, Indonesia, New Guinea and its associated islands, the Solomon Islands, and northern and eastern Australia (Shine, 1991). Since its accidental introduction to the island of Guam sometime during the late 1940 s or early 1950 s, it has irrupted with population densities occasionally reaching 50 to 100 snakes/ha (Rodda et al., 1992). Such densities are un- 
usually high compared to other snake species (Rodda et al., 1999a). The brown treesnake has been implicated in the extirpation of most of Guam's native bird fauna and in contributing to the decline of native lizard and small mammal populations (Wiles, 1987; Rodda and Fritts, 1992). Extensive efforts are under way to develop methods for reducing snake densities on Guam, thereby reducing its chances of spreading to other equally susceptible Pacific islands (Brown Treesnake Control Committee, 1996). The U.S. Geological Survey and the National Wildlife Research Center of the Animal and Plant Health Inspection Service are currently conducting studies on the reproductive biology of the brown treesnake on Guam because the efficacy of a number of control programs may depend on such information. As part of this effort, one of our goals is to determine whether brown treesnakes exhibit seasonal hormonal cycles on Guam.

A major consideration in such studies is the possible influence of capture stress on plasma concentrations of sex steroids (for a review, see Guillette $e t$ al., 1995). Glucocorticosteroids are the primary endocrine secretions mediating vertebrate adaptation to stress (Axelrod and Reisine, 1984; Munck et al., 1984), and it is well known that increased levels of glucocorticosteroids can cause marked and rapid changes in levels of sex steroids (Greenberg and Wingfield, 1987; Elsey et al., 1991; Moore et al., 1991). Brown treesnakes are most easily obtained by live trapping at night and then collecting them from traps during the day. When observed in traps during daylight hours, they appear quiescent; that is, they are almost invariably coiled in their characteristic resting posture and often behave lethargically while being removed from traps. Despite these observations, there was concern that plasma levels of stress and reproductive hormones could be affected by residence in a trap and particularly by the process of removing snakes from traps and holding them briefly in captivity. To address these concerns, we determined (1) the extent to which residence in a trap and subsequent handling affects levels of circulating corticosterone and (2) the relationship between plasma concentrations of corticosterone and testosterone and progesterone. Corticosterone is the principal glucocorticosteroid in reptiles (Callard and Callard, 1978; Greenberg and Wingfield, 1987).

\section{MATERIALS AND METHODS}

\section{Field Methods}

Brown treesnakes were sampled along the margins of secondary growth forest near Tamuning $\left(13^{\circ} 30^{\prime} \mathrm{N}\right.$, $144^{\circ} 48^{\prime} \mathrm{E}$ ), Guám, from July 15 to 25,2000 , during the early part of the rainy season. There were five treatment groups: (1) free-ranging snakes that were handcaptured and bled immediately, (2) snakes that spent 1 night in traps that were taken from traps and bled immediately, (3) snakes that spent 3 nights in traps that were taken from traps and bled immediately, (4) snakes that spent 1 night in traps that were then held in cloth bags in the field for $10 \mathrm{~min}$ and then bled immediately, and (5) snakes that spent 1 night in traps that were then held in cloth bags in the field for $2 \mathrm{~h}$ and then bled immediately. Snakes in the free-ranging group were collected from chain-link fence lines in the evening between 2000 and $2300 \mathrm{~h}$ at the beginning of their nightly activity period. Snakes in all other groups were collected from traps during the day between 0700 and $1330 \mathrm{~h}$.

The traps $(50 \mathrm{~cm}$ long $\times 21 \mathrm{~cm}$ diameter) were constructed from wire hardware cloth and had a oneway door at each end through which snakes could enter but not exit. Each trap was baited with a live mouse placed within a protective wire-mesh box within the trap. Mice were provided with a feed block and a fresh potato for liquid. A thin sheet of opaque plastic covered the top of each trap and protected the animals inside from direct exposure to rain and sunlight. Traps were affixed 0.5 to $2.0 \mathrm{~m}$ above the ground on trees or chain-link fencing at 30-m intervals along the forest edge. Traps were checked daily so that the night a snake entered a trap was known. If we intended to leave a snake in its trap for 3 nights, then we noted the trap identification number and the relative body size of the snake. The trap number enabled us to avoid approaching and possibly disturbing a snake before its sampling date. The information on body size could often be used to distinguish the original inhabitant of the trap from other individuals that entered the trap on subsequent nights ( 9 cases). If we could not unequivocally determine the identify of an individual and the night it entered a trap, then it was not sampled. 
Blood was collected from the heart using a sterile syringe and was stored on ice in heparinized (lithium) tubes for 1 to $4 \mathrm{~h}$ before centrifugation. Each snake was euthanized immediately after it was bled by placing it in a cloth bag on a wire mesh stand situated above a cloth pad soaked with Halothane (Halocarbon Products Corporation, River Edge, New Jersey) within a sealed plastic container. Carcasses were then sealed in plastic bags and kept frozen until taking morphological measurements. We measured snout-vent length (SVL) to the nearest millimeter and determined sex by probing for hemipenes. Male SVLs ranged from 589 to $1290 \mathrm{~mm}$ (mean $=963.7 \mathrm{~mm}, S E=21.4, n=76)$. Female SVLs ranged from 592 to $1224 \mathrm{~mm}$ (mean = $914.1 \mathrm{~mm}, S E=14.0, n=76$ ). We classified males with SVLs greater than $1000 \mathrm{~mm}$ and females with SVLs greater than $960 \mathrm{~mm}$ as potentially reproductively mature (Rodda et al., 1999b). The sex of males that were judged to be reproductively mature was confirmed by dissections. The ovaries of the females that were judged to be reproductively mature were dissected out, and the follicles were classified as either acquiring yolk (follicle diameter $>5 \mathrm{~mm}$, yellow in color) or not yolked (follicle diameter $<5 \mathrm{~mm}$, white to pale yellow in color). If follicles were classified as acquiring yolk, then the entire ovary was weighed to the nearest 0.01 gram. The dissections revealed no cases where sex was misidentified based on probing for hemipenes, indicating that our probing technique was reliable.

\section{Factors Affecting Plasma Concentrations of Corticosterone}

Diel patterns in corticosterone can confound comparisons of plasma corticosterone concentration (Chan and Callard, 1972; Lance and Lauren, 1984; DauphinVillemant and Xavier, 1987). Although it would have been desirable to sample free-ranging brown treesnakes during the day when we sampled snakes in traps, it was logistically impossible to locate sufficient numbers of snakes during the day because they are relatively secretive at this time. Therefore, we restricted our nighttime sampling of free-ranging snakes to the early evening hours when they first become active and when levels of corticosterone would presumably be closer to daytime levels. Preliminary regression analyses conducted for each sex within the free-ranging group and the two groups that were bled immediately after being taken from traps revealed no cases where corticosterone concentration varied significantly $\left(P^{\prime} s>0.05\right)$ with time of day. Therefore, this variable was not included in any further analyses.

The stress associated with the time required to capture a snake or to remove it from a trap and obtain a blood sample could also confound comparisons of corticosterone levels (Moore et al., 1991; Dunlap, 1993). Therefore, we recorded the length of time (in seconds) that it took to catch each free-ranging snake or to remove each snake from its trap and obtain a blood sample. All blood samples were taken in less than 13 min (mean $=3.1 \pm 0.15 \mathrm{~min}$ ). Preliminary regression analyses conducted for each sex within the free-ranging group and the two groups that were bled immediately after being taken from traps revealed two cases of a significant correlation between corticosterone concentration and time required to obtain a blood sample (i.e., snakes that spent 1 night in traps that were taken from traps and bled immediately, males and females). However, when sample collection times greater than 8 min were deleted from these analyses, neither analysis remained significant. Therefore, hormonal data for individuals with sample collection times greater than 8 $\min (n=4)$ were excluded from the analyses, and this variable was not included in any further analyses.

Plasma concentrations of corticosterone may also vary with body temperature (Girling and Cree, 1995; Tyrrell and Cree, 1998). Therefore, immediately after collecting blood, we used a thermocouple thermometer to measure ambient air temperature at the position where each free-ranging snake was captured or shaded ambient temperature at the position where each snake-containing trap was situated. We assume that the body temperatures of snakes were close to ambient air temperatures because all snakes were perched on wire at least $0.5 \mathrm{~m}$ above the ground (i.e., all free-ranging snakes were on chain-link fencing, and snakes in traps were on wire mesh). Most traps were situated in shade, but for those that were not, the plastic sheets covering the tops of the traps kept snakes shaded. Shaded air temperatures measured during daytime sampling ranged from 23.6 to $31.8^{\circ}$ (mean $\left.=27.3 \pm 0.2^{\circ}\right)$ and temperatures measured during evening sampling ranged from 23.5 to $26.1^{\circ}$ $\left(\right.$ mean $\left.=24.6 \pm 0.1^{\circ}\right)$. Preliminary regression analyses conducted for each sex within the free-ranging group 
and the two groups that were bled immediately after being taken from traps revealed no significant correlations between plasma corticosterone concentration and air temperature. This variable, therefore, was not included in any further analyses.

\section{Radioimmunoassays}

Blood samples were centrifuged for $3 \mathrm{~min}$, and the plasma was stored at $-20^{\circ}$. Samples were then transported to the National Wildlife Research Center (NWRC) in Fort Collins, Colorado, and stored at $-70^{\circ}$ until assayed for testosterone and progesterone. Plasma for the corticosterone assays was shipped from the NWRC to the Center for Reproduction of Endangered Species in San Diego and stored at $-20^{\circ}$ until analysis. Assays for all hormones were validated by parallelism of serially diluted samples of steroid-free brown treesnake plasma with the appropriate standard curve.

Corticosterone was measured in all snakes in duplicate $20-\mu 1$ aliquots of plasma. Tritiated corticosterone was obtained from DuPont NEN Products (Boston). Antibody 3R3 specific for corticosterone was obtained from ICN (Costa Mesa, CA). The extraction method and radioimmunoassay procedure was described in Lance and Lauren (1984). Assay sensitivity was 15 $\mathrm{pg} / \mathrm{ml}$. The intraassay coefficient of variation was $6.4 \%$, and the interassay coefficient of variation was $13.8 \%$. Testosterone (potentially reproductively mature males only) and progesterone (potentially reproductively mature females only) were measured in duplicate $100-\mu$ l aliquots of plasma within single assays using the methods described previously in Berndtson et al. (1974) and Niswender (1973), respectively. Assay sensitivities for testosterone and progesterone were 27 and $17 \mathrm{pg} / \mathrm{ml}$, respectively. The intraassay coefficients of variation for testosterone and progesterone were 0.14 and $6.34 \%$, respectively.

\section{Statistical Analyses}

Results are reported as mean \pm standard errors. Log transformations were used where necessary to achieve normality and homogeneous variances. A two-way analysis of variance (ANOVA) with treatment group and sex as the factors was used to compare mean plasma concentrations of corticosterone. The Games-
Howell test (Games and Howell, 1976) was used for $a$ posteriori comparisons among means by treatment group. Comparisons of means between sexes within treatment groups were made using the Student's $t$ test (two-tailed). Linear regression was used to describe the relationship between testosterone and corticosterone concentrations and the relationship between progesterone and corticosterone concentrations when correlations were significant. These regressions were based on the combined data for all treatment groups. All analyses were tested for statistical significance at the $P<0.05$ level. All statistical analyses were conducted with Statview software (version 5.0.1, Statistical Analysis Systems Institute, Cary, NC).

\section{RESULTS}

\section{Effects of Trapping and Subsequent Short-Term Confinement on Plasma Corticosterone Concentration}

All snakes observed in traps were resting in a coiled position, usually near the roof of the trap on top of one of the inward pointing wire-mesh cone/door assemblies, and most snakes remained in this position even after the traps had been taken down and opened. Mean plasma concentration of corticosterone (Table 1 and Fig. 1) differed significantly among treatment groups, $F_{(4,142)}=186.97, P<0.0001$, as well as between sexes, $F_{(1,142)}=4.29, P=0.04$, and the interaction was not significant, $F_{(4,146)}=1.53, P=0.20$. Mean plasma concentration of corticosterone of snakes that were in traps for 3 nights did not differ from that of free-ranging snakes or that of snakes that were in traps for 1 night and bled immediately ( $\left.P^{\prime} s>0.05\right)$, but all other pairwise comparisons among groups were significantly different $\left(P^{\prime} s<0.05\right)$. Mean plasma concentrations of corticosterone for males and females that were in traps for 1 night and then bled immediately were about four and two times higher, respectively, than those of free-ranging control males and females. By contrast, the mean plasma concentration of corticosterone in snakes that were in traps for 3 nights was intermediate between, but did not differ from, the means for free-ranging snakes and snakes that were in traps for 1 night. Corticosterone levels in snakes taken from traps and placed in bags increased rapidly dur- 
TABLE 1

Plasma Corticosterone Concentrations (nanograms/milliliter, means $\pm S E$ ) in Male and Female Brown Treesnakes (Boiga irregularis) Immediately after Removal from Live Traps, Subsequent Short-Term Confinement, or Capture

\begin{tabular}{lccccc}
\hline & Free-ranging & In trap 1 night & In trap 3 nights & Confined in bag 10 min & Confined in bag 2 $\mathrm{h}$ \\
\hline Males & $4.41 \pm 0.77$ & $19.02 \pm 2.97$ & $11.07 \pm 4.09$ & $35.94 \pm 4.45$ \\
$(n=18)$ & $(n=26)$ & $(n=9)$ & $13)$ & $49.30 \pm 6.16$ \\
Females & $(n=71 \pm 1.82$ & $20.44 \pm 2.23$ & $16.29 \pm 7.99$ & $(n=10)$ \\
& $(n=18)$ & $(n=26)$ & $(n=6)$ & $37.72 \pm 5.48$ & $(n=14)$ \\
\end{tabular}

Note. Snakes in the two confined treatments had spent 1 night in traps. $n=$ number of snakes sampled.

ing the first $10 \mathrm{~min}$ of holding $(\sim 1.7 \mathrm{ng} / \mathrm{ml} / \mathrm{min})$ and were about two times higher than those of control males and females that were in traps for 1 night and bled immediately. Corticosterone levels in snakes held in bags for $2 \mathrm{~h}$ continued to rise but at a much slower rate over the subsequent 1.8 -h holding period. Mean corticosterone levels of males and females in this group were at least 2.5 times higher than those of males and females that were in traps for 1 night and bled immediately. Plasma corticosterone concentrations were higher in females than in males in all five treatment groups, but the only significant difference was within the free-ranging group, $t=2.50,34 d f$, $P=0.02$.

\section{Reproductive Status and the Relationships between Plasma Concentrations of Sex Steroids and Corticosterone}

Of the 76 male and 76 female brown treesnakes in our sample, 35 males and 33 females were classified as potentially reproductively mature. However, with the

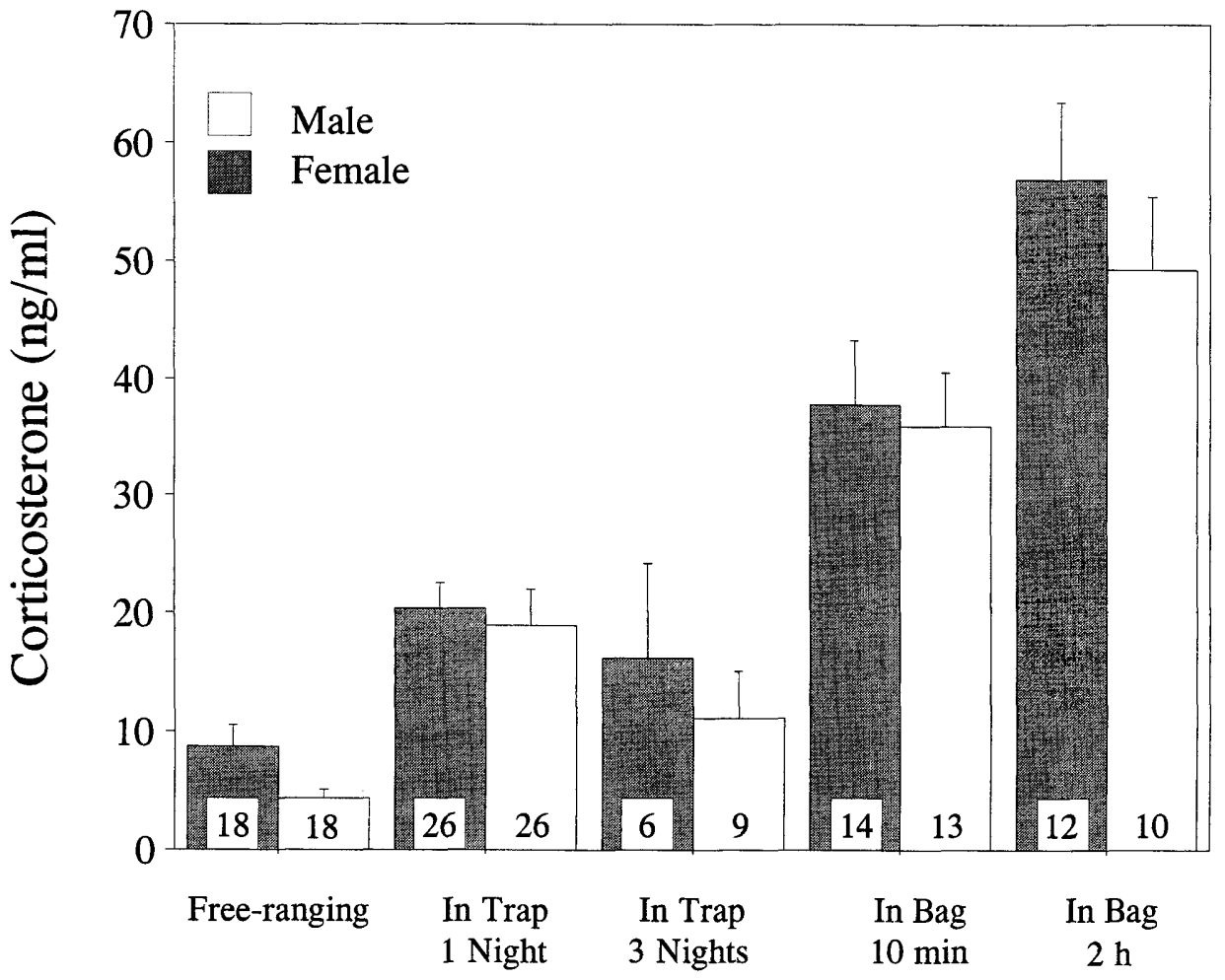

FIG. 1. Effects of residence in a live trap and subsequent short-term confinement on plasma corticosterone concentrations (means $\pm S E$ ) in male and female brown treesnakes. Sample size is given at the base of each bar. 
exception of 1 male (SVL $=1267 \mathrm{~mm}$ ) that had a relatively high plasma testosterone concentration of $15.25 \mathrm{ng} / \mathrm{ml}$ (this datum is not included in the following analyses), testosterone concentrations in males were low, ranging from 0.07 to $3.20 \mathrm{ng} / \mathrm{ml}$ (mean = $0.71 \pm 0.11 \mathrm{ng} / \mathrm{ml})$. It is unlikely that the low levels of testosterone observed were due to residence in a trap; the mean plasma concentration of testosterone for free-ranging males and that of males that were in traps for 1 night and then bled immediately did not differ, $t=0.08,16 d f, P=0.94$. Plasma testosterone was not related to plasma corticosterone, $F_{(1,33)}=1.44, P=$ 0.24 , as might be expected given such low levels of testosterone. Of the 33 females classified as potentially reproductively mature, only 2 had follicles that were unequivocally acquiring yolk. One of the 2 females contained three enlarged follicles (total ovarian mass $=14.2 \mathrm{~g}$, SVL $=970 \mathrm{~mm}$ ), and the other one contained five enlarged follicles (total ovarian mass = $16.8 \mathrm{~g}$, SVL $=1224 \mathrm{~mm}$ ). Both females had relatively high plasma concentrations of progesterone (4.67 and $1.73 \mathrm{ng} / \mathrm{ml}$, respectively), whereas levels in the other females were substantially lower, ranging from 0.003 to $0.44 \mathrm{ng} / \mathrm{ml}$. Plasma progesterone was not related to plasma corticosterone when the values for the 2 reproductive females were included in the regression analysis, $F_{(1,32)}=0.26, P=0.61$, but when excluded, the relationship was positive, $F_{(1,30)}=45.52, P<0.0001$, $R^{2}=0.60, y=-0.2+0.005 X$.

\section{DISCUSSION}

Despite the quiescent appearance of snakes in traps, levels of plasma corticosterone in these snakes were substantially elevated compared to the free-ranging controls. Residence in a trap for 1 night elicited a marked increase in plasma concentration of corticosterone, with mean levels in males and females about four and two times higher than those of the respective controls. It is notable that the magnitudes of these differences are similar to those exhibited by other species of free-ranging reptiles that have experienced the presumably more severe stress of hand capture and short-term confinement (for a review, see Tyrrell and Cree, 1998). Thus, a brief residence in a trap induces an acute stress response in brown treesnakes.
The mean plasma corticosterone for snakes that resided for 3 nights in traps was intermediate between, but not significantly different from, that for snakes that spent 1 night in traps or that for free-ranging snakes, suggesting that snakes become only somewhat acclimated to the traps over this period of time.

Removal of snakes from traps followed by confinement in a bag for 10 min elicited a further marked increase in plasma corticosterone. Mean levels of plasma corticosterone in males and females in this group were about two times higher than those of control snakes that were in traps for 1 night and were bled immediately. Corticosterone levels in snakes that were held in bags for $2 \mathrm{~h}$ after removal from traps were significantly higher than those in snakes that were held for $10 \mathrm{~min}$, suggesting that corticosterone levels continued to rise but at a much slower rate than during the first $10 \mathrm{~min}$. The only other study to examine the effects of capture stress on corticosterone secretion in a snake (Thamnophis sirtalis parietalis) found that corticosterone levels decreased significantly after $1 \mathrm{~h}$ of confinement (Whittier et al., 1987). These authors concluded that garter snakes are less susceptible to the stresses of capture and captivity than are other vertebrates. By contrast, our finding that capture stress causes a marked increase in corticosterone secretion in the brown treesnake is consistent with those for most squamates (Manzo et al., 1994; Dunlap and Wingfield, 1995; Moore et al., 1991; but see Girling and Cree, 1995), rhynchocephalians (Tyrrell and Cree, 1998), chelonians (Aguirre et al., 1995; Gregory et al., 1996), and crocodilians (Guillette et al., 1997).

The proximate cause(s) for the observed elevation of plasma corticosterone in snakes in traps is unknown, but a number of factors can be considered unlikely. Our finding that corticosterone concentrations did not increase with longer trap residence times (i.e., effect of stressor(s) is not cumulative) suggests that extrinsic factors (e.g., environmental conditions) experienced in traps were unimportant. The traps were relatively roomy and contained a number of perch sites. The wire-mesh construction allowed relatively unimpeded air flow through the traps, and the plastic coverings over traps protected snakes from direct sunlight and rainfall. The absence of a dark daytime retreat within traps or the inability to select a familiar daytime retreat were probably not factors because brown treesnakes spend the inactive daytime period in all parts 
of the landscape including exposed sites such as branches at the tops of trees and shrubs (Wiles, 1987, 1988) and generally select a new retreat each night on nights when they are active (Tobin et al., 1999; Rodda et al., 1999b). Our assessment is that snakes that have entered traps become stressed during the unsuccessful process of trying to reach the mouse bait and/or during the unsuccessful process of finding an exit from the traps. Nighttime surveillance of traps with video cameras (unmanned) equipped with infrared illumination revealed that snakes that have entered traps will first try to find a way into the enclosure containing the mouse bait but will then spend the remainder of the night apparently searching for an exit from the traps (L. Clark, personal communication). As dawn approaches, snakes cease this exploratory activity and take up their typical daytime resting posture.

A number of studies have documented a daily rhythm in corticosterone secretion in reptiles (but see Tyrrell and Cree, 1998, Sphenodon punctatus), and in those species where it occurs, maximal levels of secretion occur during the period(s) of greatest activity (Chan and Callard, 1972, Dipsosaurus dorsalis; Dauphin-Villemant and Xavier, 1987, Lacerta vivipara; Lance and Lauren, 1984, Alligator mississippiensis). If brown treesnakes exhibit a similar pattern of secretion, and if we had collected blood samples from the snakes in traps at night when they are most active, then we might have observed even higher plasma concentrations of corticosterone than those observed during the day. Thus, the differences in plasma corticosterone concentrations that we observed between snakes from traps and free-ranging snakes may be conservative.

Because of the male-biased sex ratios and the less robust body condition of female brown treesnakes observed in recent samples on Guam, Jordan and Rodda (1994) proposed that females are not meeting all of their energetic needs and may be experiencing physiological stress (see also Rodda et al., 1999a). Although our finding that plasma corticosterone of freeranging females was about two times higher than that of males is consistent with this hypothesis, the levels exhibited by free-ranging females were well within the range of basal levels observed in other reptiles when nonreproductive (for a review, see Tyrrell and Cree, 1998). However, female brown treesnakes may become physiologically stressed at some times of the year but not others. Our samples were collected over a relatively brief period and during the rainy season when food may be less limited.

The near absence of male brown treesnakes with elevated levels of testosterone in our sample may simply reflect the normal reproductive state of most males during the rainy season. The testes of most male brown treesnakes in a Papua New Guinea population are regressed during the rainy season and do not become well developed or contain mature sperm until the dry season (Bull et al., 1997). However, it should be noted that the cyclicity and seasonality of testicular development have not been thoroughly examined in Guamanian brown treesnakes, although there are some data (pooled from different years and localities) that seem to indicate that there is no obvious seasonal pattern (F. J. Qualls and J. A. Savidge, unpublished data). It is unlikely that the low levels of testosterone observed were due to the stress caused by being in a trap; the mean plasma testosterone concentration in males in the free-ranging group was also low but did not differ from that of males that were in traps for 1 night. Furthermore, the 1 male with an elevated level of testosterone was from the group that spent 1 night in traps, suggesting that we should have detected other males in our samples with similarly elevated testosterone if they had been present. The scarcity of reproductive females in our sample may also reflect the normal state of most females at that time of year. However, McCoid (1994) found no obvious seasonal pattern of female reproduction on Guam; reproductive females were found during most months of the year, indicating that reproduction may occur at any time. The 2 females with enlarged follicles in our sample are consistent with such a pattern of reproduction.

We were not able to adequately evaluate the possible effects of traps on levels of testosterone and progesterone in reproductive male and female brown treesnakes because of the paucity of such individuals in our sample. However, in nonreproductive females, there was a significant positive correlation between plasma progesterone and corticosterone, indicating that stress may influence steroidogenesis in the adrenal gland. Progesterone and corticosterone both are produced in the reptilian adrenal gland (Callard and Leatham, 1964; Highfill and Meade, 1975), and progesterone presumably serves as an intermediate in the 
of the landscape including exposed sites such as branches at the tops of trees and shrubs (Wiles, 1987, 1988) and generally select a new retreat each night on nights when they are active (Tobin et al., 1999; Rodda et al., 1999b). Our assessment is that snakes that have entered traps become stressed during the unsuccessful process of trying to reach the mouse bait and/or during the unsuccessful process of finding an exit from the traps. Nighttime surveillance of traps with video cameras (unmanned) equipped with infrared illumination revealed that snakes that have entered traps will first try to find a way into the enclosure containing the mouse bait but will then spend the remainder of the night apparently searching for an exit from the traps (L. Clark, personal communication). As dawn approaches, snakes cease this exploratory activity and take up their typical daytime resting posture.

A number of studies have documented a daily rhythm in corticosterone secretion in reptiles (but see Tyrrell and Cree, 1998, Sphenodon punctatus), and in those species where it occurs, maximal levels of secretion occur during the period(s) of greatest activity (Chan and Callard, 1972, Dipsosaurus dorsalis; Dauphin-Villemant and Xavier, 1987, Lacerta vivipara; Lance and Lauren, 1984, Alligator mississippiensis). If brown treesnakes exhibit a similar pattern of secretion, and if we had collected blood samples from the snakes in traps at night when they are most active, then we might have observed even higher plasma concentrations of corticosterone than those observed during the day. Thus, the differences in plasma corticosterone concentrations that we observed between snakes from traps and free-ranging snakes may be conservative.

Because of the male-biased sex ratios and the less robust body condition of female brown treesnakes observed in recent samples on Guam, Jordan and Rodda (1994) proposed that females are not meeting all of their energetic needs and may be experiencing physiological stress (see also Rodda et al., 1999a). Although our finding that plasma corticosterone of freeranging females was about two times higher than that of males is consistent with this hypothesis, the levels exhibited by free-ranging females were well within the range of basal levels observed in other reptiles when nonreproductive (for a review, see Tyrrell and Cree, 1998). However, female brown treesnakes may become physiologically stressed at some times of the year but not others. Our samples were collected over a relatively brief period and during the rainy season when food may be less limited.

The near absence of male brown treesnakes with elevated levels of testosterone in our sample may simply reflect the normal reproductive state of most males during the rainy season. The testes of most male brown treesnakes in a Papua New Guinea population are regressed during the rainy season and do not become well developed or contain mature sperm until the dry season (Bull et al., 1997). However, it should be noted that the cyclicity and seasonality of testicular development have not been thoroughly examined in Guamanian brown treesnakes, although there are some data (pooled from different years and localities) that seem to indicate that there is no obvious seasonal pattern (F. J. Qualls and J. A. Savidge, unpublished data). It is unlikely that the low levels of testosterone observed were due to the stress caused by being in a trap; the mean plasma testosterone concentration in males in the free-ranging group was also low but did not differ from that of males that were in traps for 1 night. Furthermore, the 1 male with an elevated level of testosterone was from the group that spent 1 night in traps, suggesting that we should have detected other males in our samples with similarly elevated testosterone if they had been present. The scarcity of reproductive females in our sample may also reflect the normal state of most females at that time of year. However, McCoid (1994) found no obvious seasonal pattern of female reproduction on Guam; reproductive females were found during most months of the year, indicating that reproduction may occur at any time. The 2 females with enlarged follicles in our sample are consistent with such a pattern of reproduction.

We were not able to adequately evaluate the possible effects of traps on levels of testosterone and progesterone in reproductive male and female brown treesnakes because of the paucity of such individuals in our sample. However, in nonreproductive females, there was a significant positive correlation between plasma progesterone and corticosterone, indicating that stress may influence steroidogenesis in the adrenal gland. Progesterone and corticosterone both are produced in the reptilian adrenal gland (Callard and Leatham, 1964; Highfill and Meade, 1975), and progesterone presumably serves as an intermediate in the 
biosynthesis of corticosterone (Hadley, 1996). Capture stress also was associated with a significant increase in plasma progesterone in female snapping turtles (Chelydra serpentina), many of which were vitellogenic (Mahmoud et al., 1989). A pronounced stress-induced elevation of progesterone has also been observed in male and female tuatara (Cree et al., 1990; some females were gravid [Tyrrell and Cree, 1998]). By comparison with the latter study, the increase in progesterone that we observed in brown treesnakes was trivial despite their much higher levels of corticosterone; the slopes of the regressions for progesterone and corticosterone for male and female tuatara were 19 and 32 times steeper, respectively, than that for female brown treesnakes. Therefore, it seems unlikely that acute stress would unduly influence levels of progesterone in female brown treesnakes when reproductive, but this remains to be determined. The effects of acute stress on plasma levels of estradiol have not been investigated in any squamate, but in female alligators (Alligator mississippiensis) that were captured, restrained, and repeatedly bled, estradiol levels declined substantially over a $22-\mathrm{h}$ period (Elsey et al., 1991).

An inherent difficulty in profiling the reproductive hormonal cycle of female brown treesnakes on Guam is that gravid females are rarely encountered, in part because reproduction may be spread out over most of the year (McCoid, 1994) but also because they may become more secretive when gravid (Rodda et al., 1999b). In light of the results of the current study, a further difficulty is that trapping induces stress in both sexes that could, in turn, affect levels of reproductive hormones. Trapping is the most productive method currently available for collecting brown treesnakes. However, unless it can be shown that residence in a trap does not greatly affect levels of reproductive hormones, studies on the hormonal cycles of brown treesnakes would best be based on free-ranging snakes.

\section{ACKNOWLEDGMENTS}

We thank D. Vice and the personnel under his supervision at the U.S. Department of Agriculture/Wildlife Services for use of their facilities and logistical assistance on Guam. Xiao Miang at the
Endocrine Laboratory of Colorado State University conducted the testosterone and progesterone assays. R. Andrews, L. Miller, G. Rodda, P. Savarie, and J. Wimsatt provided comments on earlier drafts of this article. This project was conducted with funds provided by the U.S. Department of Defense Legacy Project 0079, "Exploratory Reproductive Inhibition in the Brown Treesnake." All fieldwork was done according to NWRC study protocol QA-828 and was.approved by the NWRC Animal Care and Use Committee.

\section{REFERENCES}

Aguirre, A. A., Balazs, G. H., Spraker, T. R., and Gross, T. S. (1995). Adrenal and hematological responses to stress in juvenile green turtles (Chelonia mydas) with and without fibropapillomas. Physiol. Zool. 68, 831-854.

Axelrod, J., and Reisine, T. D. (1984). Stress hormones: Their interaction and regulation. Science 224, 452-459.

Berndtson, W. E., Pickett, B. W., and Nett, T. M. (1974). Reproductive physiology of the stallion. IV. Seasonal changes in the testosterone concentration of peripheral plasma. J. Rep. Physiol. 39, 115-118.

Brown Treesnake Control Committee. (1996). "The Brown Treesnake Control Plan." Prepared by the Brown Treesnake Control Committee, Aquatic Nuisance Special Task Force U.S. Fish and Wildlife Service, Honolulu, Hawaii.

Bull, K. H., Mason, R. T., and Whittier, J. (1997). Seasonal testicular development and sperm storage in tropical and subtropical populations of the brown tree snake (Boiga irregularis). Austral. J. Zool. 45, 479-488.

Callard, I. P., and Callard, G. V. (1978). General, comparative, and clinical endocrinology of the adrenal cortex. In "The Adrenal Gland in Reptilia," Part 2: "Physiology" (I. C. Jones and I. W. Henderson, Eds.), pp. 370-418. Academic Press, New York.

Callard, I. P., and Leatham, J. H. (1964). In vitro synthesis of progesterone by ovaries and adrenals of snakes. Proc. Soc. Exp. Biol. Med. 115, 567-569.

Chan, S. W. C., and Callard, I. P. (1972). Circadian rhythm in the secretion of corticosterone by the desert iguana, Dipsosaurus dorsalis. Gen. Comp. Endocrinol. 18, 565-568.

Cree, A., Guillette, L. J., Jr., Cockrem, J. F., Brown, M. A., and Chambers, G. K. (1990). Absence of daily cycles in plasma sex steroids in male and female tuatara (Sphenodon punctatus), and the effects of acute capture stress on females. Gen. Comp. Endocrinol. 79, 103-113.

Dauphin-Villemant, C., and Xavier, F. (1987). Nychthemeral variations of plasma corticosteroids in captive female Lacerta vivipara Jacquin: Influence of stress and reproductive state. Gen. Comp. Endocrinol. 67, 292-302.

Dunlap, K. D. (1993). "Hormonal, Physiological, and Behavioral Responses of Fence Lizards Facing Severe Drought and Malarial Parasitism." Ph.D. dissertation, University of Washington.

Dunlap, K. D., and Wingfield, J. C. (1995). External and internal influences on indices of physiological stress. I. Seasonal and population variation in adrenocortical secretion of free-living lizards, Sceloporus occidentalis. J. Exp. Zool. 271, 36-46. 
Elsey, R. M., Lance, V. A., Joanen, T., and McNease, L. (1991). Acute stress suppresses plasma estradiol levels in female alligators ( $\mathrm{Al}$ ligator mississippiensis). Comp. Biochem. Physiol. A. 100, 649-651.

Games, P. A., and Howell, J. F. (1976). Pairwise multiple comparison procedures with unequal $n$ 's and/or variances: A Monte Carlo study. J. Educ. Stat. 1, 113-125.

Girling, J. E., and Cree, A. (1995). Plasma corticosterone levels are not significantly related to reproductive stage in female common geckoes (Hoplodactylus maculatus). Gen. Comp. Endocrinol. 100, 273281.

Greenberg, N., and Wingfield, J. C. (1987). Stress and reproduction: Reciprocal relationships. In "Hormones and Reproduction in Fishes, Amphibians, and Reptiles" (D. O. Norris and R. E. Jones, Eds.), pp. 461-503. Plenum, New York.

Gregory, L. F., Gross, T. S., Bolten, A. B., Bjorndal, K. A., and Guillette, L. J., Jr. (1996). Plasma corticosterone concentrations associated with acute captivity stress in wild loggerhead sea turtles (Caretta caretta). Gen. Comp. Endocrinol. 104, 312-320.

Guillette, L. J., Jr., Crain, D. A., Rooney, A. A., and Woodward, A. R. (1997). Effect of acute stress on plasma concentrations of sex and stress hormones in juvenile alligators living in control and contaminated lakes. J. Herpetol. 31, 347-353.

Guillette, L. J., Jr., Cree, A., and Rooney, A. A. (1995). Biology of stress: Interactions with reproduction, immunology, and intermediary metabolism. In "Health and Welfare of Captive Reptiles" (C. Warwick, F. L. Frye, and J. B. Murphy, Eds.), pp. 32-81. Chapman \& Hall, London.

Hadley, M. E. (1996). "Endocrinology," 4th ed. Prentice Hall, London.

Highfill, D. R., and Meade, R. A. (1975). Sources and levels of progesterone during pregnancy in the garter snake, Thamnophis elegans. Gen. Comp. Endocrinol. 27, 369-400.

Jordan, M. A., and Rodda G. H. (1994). Identification of sex in Boiga irregularis: Implications for understanding population dynamics in Guam. J. Herpetol, 28, 381-384.

Lance, V. A., and Lauren, D. (1984). Circadian variation in plasma corticosterone in the American alligator, Alligator mississippiensis, and the effects of ACTH injections. Gen. Comp. Endocrinol. 54, 1-7.

Mahmoud, I. Y., Guillette, L. J., Jr., McAsey, M. E., and Cady, C. (1989). Stress-induced changes in serum testosterone, estradiol$17 \beta$, and progesterone in the turtle Chelydra serpentina. Comp. Biochem. Physiol. A. 93, 423-427.

Manzo, C., Zerani, M., Gobbetti, A., DiFiore, M. M, and Angelini, F. (1994). Is corticosterone involved in reproductive processes of the male lizard, Podarcis sicula sicula? Horm. Behav. 28, 117-129.

McCoid, M. J. (1994). Boiga irregularis (brown tree snake) reproduction. Herpetol. Rev. 25, 69-70.
Moore, M. C., Thompson, C. W., and Marler, C. A. (1991). Reciprocal changes in corticosterone and testosterone following acute and chronic handling stress in the tree lizard, Urosaurus ornatus. Gen. Comp. Endocrinol. 81, 217-226.

Munck, A., Guyre, P. M., and Holbrook, N. J. (1984). Physiological functions of glucocorticoids in stress and their relation to pharmacological actions. Endocrine Rev. 5, 25-44.

Niswender, G. D. (1973). Influence of the site of conjugation on specificity of antibody to progesterone. Steroids 22, 413-424.

Rodda, G. H., and Fritts, T. H. (1992). The impact of the introduction of the brown treesnake, Boiga irregularis, on Guam's lizards. J. Herpetol. 26, 166-174.

Rodda, G. H., Fritts, T. H., and Conry, P. J. (1992). Origin and population growth of the brown treesnake, Boiga irregularis, on Guam. Pacific Sci. 46, 46-57.

Rodda, G. H., Fritts, T. H., McCoid, M. J., and Campbell, E. W., III. (1999a). Population trends and limiting factors in Boiga irregularis. In "Problem Snake Management: The Habu and the Brown Treesnake" (G. H. Rodda, Y. Sawai, D. Chiszar, and H. Tanaka, Eds.), pp. 236-253. Cornell Univ. Press, Ithaca, NY.

Rodda, G. H., McCoid, M. J., Fritts, T. H., and Campbell, E. W., III. (1999b). An overview of the biology of the brown treesnake, Boiga irregularis, a costly introduced pest on Pacific Islands. In "Problem Snake Management: The Habu and the Brown Treesnake" (G. H. Rodda, Y. Sawai, D. Chiszar, and H. Tanaka, Eds.), pp. 44-80. Cornell Univ. Press, Ithaca, NY.

Shine, R. (1991). Strangers in a strange land: Ecology of Australian colubrid snakes. Copeia. 1999, 120-131.

Tobin, M. E., Sugihara, R. T., Pochop, P. A., and Linnel, M. A. (1999). Nightly and seasonal movements of Boiga irregularis on Guam. J. Herpetol. 33, 281-291.

Tyrrell, C. L., and Cree, A. (1998). Relationships between corticosterone concentration and season, time of day, and confinement in a wild reptile (Tuatara, Sphenodon punctatus). Gen. Comp. Endocrinol. 110, 97-108.

Whittier, J. M., Mason, R. T., and Crews, D. (1987). Plasma steroid hormone levels of female red-sided garter snakes, Thamnophis sirtalis parietalis: Relationships to mating and gestation. Gen. Comp. Endocrinol. 67, 33-43.

Wiles, G. H. (1987). Current research and future management of Marianas fruit bats (Chiroptera: Pteropodidae) on Guam. Austral. Mammalogy 10, 93-95.

Wiles, G. H. (1988). Movements, home range, and activity patterns of the brown treesnake. In "Annual Report, Fiscal Year 1987, Guam Aquatic and Wildlife Resources Division" (G. R. Grimm and L. L. Mariano, Eds.), pp. 139-142. Department of Agriculture, Mangilao, Guam. 